\title{
Teens in trouble: cigarette use and risky behaviors among private, high school students in La Paz, Bolivia
}

\author{
Kirk A. Dearden, ${ }^{1}$ Benjamin T. Crookston, ${ }^{2}$ Natalie G. De La Cruz, ${ }^{3}$ \\ Gordon B. Lindsay, ${ }_{4}^{4}$ Ali Bowden, ${ }^{4}$ Liz Carlston, ${ }^{4}$ and Paul Gardner ${ }^{4}$
}

Suggested citation Dearden KA, Crookston BT, De La Cruz NG, Lindsay GB, Bowden A, Carlston L, et al. Teens in trouble: cigarette use and risky behaviors among private, high school students in La Paz, Bolivia. Rev Panam Salud Publica. 2007;22(3):160-8.

ABSTRACT Objective. To describe the prevalence of cigarette smoking and to identify risky behaviors associated with smoking among adolescents attending high schools in a district of La Paz, Bolivia. Methods. The Youth Risk Behavior Survey was administered to a sample of 394 males and 182 females, from 13-18 years of age, at six, randomly-selected schools in District II of La Paz. Frequencies, chi-square tests, and logistic regression were employed to identify factors associated with cigarette use during the 30 days prior to the survey.

Results. Approximately $40 \%$ of the sample (39.4\% of males and $33.7 \%$ of females) had smoked cigarettes in the 30 days prior to interview. For both males and females, consumption of alcohol was the single greatest risk factor associated with cigarette use. The males and females who reported consuming at least one alcoholic beverage on three or more occasions in the previous 30 days were 22.3 and 58.5 times (95\% CIs: 6.7, 74.1 and 6.8, 502.6, respectively) more likely to smoke tobacco than those who reported no alcohol consumption. Additional risk factors included having participated in a physical fight, having carried a weapon, having had sexual intercourse, and having used illicit drugs during the previous 30 days.

Conclusions. Because teenagers who smoke are also likely to engage in a variety of other risky behaviors, parents, school administrators, and health educators may wish to use smoking to identify at-risk individuals. Among Bolivian teenagers, interventions should focus on preventing cigarette use and associated risk behaviors.

Key words Adolescent, adolescent behavior, smoking, risk-taking, Bolivia.

Boston University School of Public Health, Department of International Health, Boston, Massachusetts, United States of America (USA). Send correspondence to: Kirk Dearden, DrPH, MPH, Associate Professor, Department of International Health and Center for International Health and Development, Boston University School of Public Health, 85 East Concord Street, Boston, Massachusetts, 02118-2526, USA; telephone: 01-617 414-1451; fax: 01- 617 414-1261.

2 University of Utah School of Medicine, Department of Family and Preventive Medicine, Salt Lake City, Utah, USA.
Smoking is one of the most important contributors to many forms of cancer, heart disease, respiratory disorders, and other noncommunicable diseases, and has been identified by

\footnotetext{
3 University of Alabama at Birmingham School of Public Health, Department of Health Behavior, Birmingham, Alabama, USA.

4 Brigham Young University, Department of Health Science, Provo, Utah, USA.
}

the World Health Organization (WHO) as the second leading cause of mortality worldwide (1). Each year approximately 5 million deaths are attributed to cigarette smoking, and if present smoking patterns remain unchanged, the number of annual tobacco-related deaths is expected to double by 2010. Seventy percent of such deaths will occur in developing countries (1). In 
the Western Hemisphere alone, onethird of all heart disease and cancers can be attributed to cigarette use (2). Despite the efforts by the Pan American Health Organization (PAHO), ministries of health, and various nonprofit organizations to curb the tobacco epidemic in the Americas, smoking prevalence in many countries in the Region has remained relatively unchanged over the past decade, and no country has fully implemented policies to decrease smoking among its population (2).

Adolescence has been identified as a "crucial life stage for preventing tobacco use and its consequences" because this is when most individuals initiate smoking (3). In the United States of America (U.S.), for example, $50 \%$ of current smokers started smoking before they reached 14 years of age; $90 \%$ had started before they turned 19 (4). Likewise, a global, crosscountry comparison of cigarette use revealed that among smokers 13-15 years of age, $23 \%$ had begun before 10 years of age (5). Due in part to the addictive nature of nicotine, individuals who begin smoking at a young age are more likely to become regular and/or heavy smokers and to get sick or die from smoking-attributable causes (6). As such, smoking prevention and cessation interventions directed towards youth must remain a public health priority, especially in countries where a considerable percentage of youth smoke.

The rate of smoking in the Region of the Americas is the third highest in the world, behind Europe and the Western Pacific (7). Within the Americas, rates of teenage smoking, particularly in Latin America, remain worthy of concern. The Global Youth Tobacco Survey (GYTS), 1999-2001, revealed that in more than half of the sites surveyed in the Americas, at least $20 \%$ of adolescents from 13 to 15 years of age currently smoke (8). The Southern Cone countries (Argentina, Chile, Paraguay, and Uruguay) showed the greatest proportion of teenage smokers, with $40 \%$ of Chilean teens reporting regular cigarette use. The Andean area (Bolivia, Columbia, Ecuador,
Peru, and Venezuela) had the second highest smoking rates among teenagers. In addition, in parts of the Andean and Southern Cone areas, one in four nonsmoking respondents reported an intention to start smoking soon (8). Such rates of cigarette use and smoking intentions portend an increase in the prevalence of chronic diseases, as well as poor health, economic outcomes, and mortality.

In addition to the negative, direct consequences of cigarette smoking, research shows that teenage smokers often engage in other risky behaviors that contribute to poor health $(3,9-12)$. Tobacco is referred to as a "gateway drug" because teens who smoke will often experiment with other drugs thereafter (3, 13-15). In addition, teen smoking has been linked to the early initiation of sexual activity and multiple sexual partners (16), delinquency, poor academic performance, and violence (10). Jocelyn Elders, former U.S. Surgeon General, stated:

When a young person starts to smoke or use tobacco, it is a signal, an alarm that he or she may get involved in other risky behaviors. This is one of the few early warning signs we have in public health. If we can prevent tobacco use in the first place, we might have a big impact on preventing or delaying a host of other destructive behaviors among our young people (17).

Understanding and addressing the relationships between cigarette smoking and other behaviors is critical to protecting the health of adolescents and to improving the health outcomes of the whole population. Youth constitute a large portion of Bolivia's population$40 \%$ of the total population is under 15 years of age (18). Given the high rates of smoking among youth in the Andean region, a better understanding of the risk factors and behaviors associated with smoking in Bolivia is timely. The 2000 GYTS in La Paz revealed that nearly one in three $(31.3 \%)$ adolescents from 13 to 15 year of age were current smokers. More than $10 \%$ began smoking before 10 years of age. These per- centages have most likely increased in recent years since $28 \%$ of those who were nonsmokers in 2000 reported that they planned to start smoking within the next year. In contrast, $64.7 \%$ of current smokers reported that they would like to quit, with $66.9 \%$ reporting an unsuccessful attempt to do so in the year preceding the survey. Of teens surveyed, nearly $20 \%$ felt that, in general, smokers had more friends; $40 \%$ were being exposed to second-hand smoke in their homes; $88 \%$ were aware of tobacco advertising on local billboards; and $82 \%$ were able to purchase tobacco despite being underage (8). Monitoring the prevalence of smoking and other risky behaviors among teens is imperative because it allows researchers to recognize potential associations between these behaviors and to plan and implement appropriate health interventions for this high-risk population. The purpose of this article is to determine the prevalence of cigarette smoking among a group of private high school students from 13 to 18 years of age in La Paz, Bolivia, and to identify risk factors and behaviors associated with cigarette use. We also highlight programmatic implications and provide suggestions for further research.

\section{MATERIALS AND METHODS}

This study is part of a larger research project investigating risky behaviors among teens in Bolivia, the Philippines, and the Ukraine. The methods for the umbrella project are described in more detail elsewhere (19). A summary of the methods used for the present study follows.

\section{Instrument}

The Youth Risk Behavior Surveillance Survey (YRBSS) was developed in 1990 by the U.S. Centers for Disease Control and Prevention (CDC) for the purpose of analyzing and monitoring trends related to six priority areas of risk behavior among high school youth (from 13 to18 years of age) (20, 21). Priority areas for the YRBSS are: 
(1) behaviors that contribute to intentional and unintentional injuries; (2) drug and alcohol use; (3) sexual behaviors resulting in unintended pregnancies and sexually-transmitted infections, including HIV infection; (4) tobacco use; (5) unhealthy dietary behaviors; and (6) low levels of physical activity, including levels of overweight (21).

For this study, the YRBSS was translated by the first author, Kirk A. Dearden, who is fluent in Spanish, and then verified by a professional translator. Some questions, such as those regarding region of residence, ethnicity, grade in school, and academic performance, were modified to reflect the local language, culture, and practices. Officials at the Servicio Departamental de Educación (SEDUCA, Department of Education) and school administrators reviewed and approved the survey instrument and received details about the data collection methods. The Spanish version of the YRBSS was then administered to high school students in District II of La Paz, Bolivia. A review of the responses indicated that no questions consistently caused difficulties for participants.

\section{Sample selection}

The Director of the SEDUCA granted permission to conduct the study, but limited it to District II schools in La Paz. From a list of District II schools ( $n=287), 15$ were randomly selected. Of these 15, three were omitted due to a strike among public school teachers that began on May 10, 2004, and extended beyond the data-collection period into June, 2004. Also purged from the list of 15 were nursery schools $(n=$ $1)$, primary schools $(n=1)$, schools that had been closed or could not be located $(n=2)$, schools that denied permission to conduct the survey $(n=1)$, and those where the majority of the student body was too young to participate $(n=1)$. One of the private schools included in the study was affiliated with a religious institution; the rest were secular. The six schools that participated were, on average, middle class, though students from all social classes were represented.

Though schools were randomly selected, the eligible students, 13 to 18 years of age, were chosen by the headmasters. Each of the six, randomlyselected schools was visited individually until at least 500 students had completed the questionnaire. This resulted in a total sample of 576 students from across the six schools.

\section{Data collection}

Each participant signed an informedconsent agreement acknowledging that their participation was voluntary, anonymous, and would not affect their grades, and that responses would remain confidential. Two Spanishspeaking undergraduate students from Brigham Young University (Provo, Utah, U.S.) administered the paperand-pencil survey during regular classroom hours. The high school respondents sat in individual desks with adequate privacy and were given as much time as needed to complete the survey.

\section{Data analysis}

All data were entered using EpiInfo (version 6.0, CDC, Atlanta, Georgia,
U.S.) and analyzed using SAS statistical software (version 9.1, SAS Institute Inc., Cary, North Carolina, U.S.). Percentages, Pearson chi-square tests, and Fisher's Exact Test were used to compare males and females separately for a variety of risk factors.Logistic regression models were used to identify factors associated with teenage smoking, adjusting for sociodemographic correlates. Variables were added to the model based on a priori hypotheses, current literature, and associations found while performing bivariate analyses. Variables were retained or dropped from regression models based on $P$ values (<0.15), the Wald statistic, estimated coefficients, and changes in the likelihood ratio test. Interaction terms were included, and all models were checked for overfitting. Odds ratios (OR) and 95\% confidence intervals $(95 \% \mathrm{CI})$ were calculated for retained variables.

\section{RESULTS}

Of the survey respondents, more than two-thirds $(68.4 \%)$ were male (Table 1), just under half were from 15 to 16 years of age, and most had academic performance of "average or better." Cigarette use in the 30 days preceding the survey was about the same for males $(39.4 \%)$ and females $(33.7 \%)$.

TABLE 1. Characteristics of survey participants, Youth Risk Behavior Survey, La Paz, Bolivia, 2004

\begin{tabular}{lcr}
\hline \multicolumn{1}{c}{ Characteristic } & $n$ & $\%$ \\
\hline Age (years) & 574 & \\
13-14 & & 26.0 \\
15 & & 20.0 \\
16 & & 27.4 \\
$17-18$ & 576 & 26.7 \\
Sex & & \\
$\quad$ Female & & 31.6 \\
$\quad$ Male & 541 & 68.4 \\
Ethnicity & & 71.7 \\
$\quad$ Mestizo/indigenous/dark complexion & & 7.2 \\
Mulatto/afro-Bolivian & 563 & 21.1 \\
White & & \\
Academic performance & & 20.3 \\
0-40 (low) & & 40.5 \\
41-50 & & 39.3 \\
51-70 (high) & & \\
\hline
\end{tabular}


TABLE 2. Tobacco use by sex, Youth Risk Behavior Survey, La Paz, Bolivia, 2004

\begin{tabular}{|c|c|c|c|}
\hline Characteristic & $\begin{array}{c}\begin{array}{c}\text { Female } \\
(n=182)\end{array} \\
\%\end{array}$ & $\begin{array}{c}\begin{array}{c}\text { Male } \\
(n=394)\end{array} \\
\frac{\%}{2}\end{array}$ & $P$ value \\
\hline Has "ever smoked" a cigarette & & & $<.0001$ \\
\hline Yes & 46.2 & 65.0 & \\
\hline Age when smoked first cigarette & & & .0005 \\
\hline Never smoked & 53.9 & 35.7 & \\
\hline 12 years or younger & 11.2 & 18.5 & \\
\hline $13-14$ years & 17.4 & 25.5 & \\
\hline 15 years or older & 17.4 & 20.3 & \\
\hline How many days did you smoke in the last 30 & & & .6039 \\
\hline 0 & 66.3 & 60.6 & \\
\hline $1-2$ & 16.0 & 17.7 & \\
\hline $3-9$ & 8.6 & 11.3 & \\
\hline 10 or more & 9.1 & 10.5 & \\
\hline Cigarettes per day in the last 30 days & & & .6076 \\
\hline Never smoked & 64.3 & 59.1 & \\
\hline Less than 1 & 13.2 & 15.9 & \\
\hline 1 & 12.1 & 12.0 & \\
\hline 2 or more & 10.4 & 13.0 & \\
\hline Cigarette source & & & .0788 \\
\hline Never smoked & 65.4 & 58.2 & \\
\hline Personally purchased & 22.9 & 32.1 & \\
\hline Another person provided them & 11.7 & 9.7 & \\
\hline Days smoked cigarettes on school property & & & .5777 \\
\hline 0 days & 91.7 & 90.2 & \\
\hline 1 or more days & 8.3 & 9.8 & \\
\hline Ever smoked cigarettes daily & 3.3 & 2.8 & .7457 \\
\hline Ever tried to quit smoking & & & .0373 \\
\hline Didn't smoke in the last 30 days & 68.9 & 57.7 & \\
\hline Yes & 20.0 & 28.4 & \\
\hline No & 11.1 & 13.9 & \\
\hline
\end{tabular}

However, there were significant differences between males and females with respect to some tobacco smoking behaviors (Table 2); for example, $65 \%$ of males had tried smoking tobacco at least once, whereas only $46.2 \%$ of females had tried it. On the other hand, females were just as likely as males to have smoked daily and to have smoked on school property. Furthermore, there was no significant difference between the sexes with regard to the quantity of cigarettes smoked per day.

With few exceptions, risk factors for having smoked during the previous 30 days were similar for males and females: age, low academic performance, having carried a weapon, having been threatened or injured with a weapon on school property, having been in a physical fight, having witnessed adults hurting others, attempting suicide, drinking, having used marijuana, and having had sexual in- tercourse (Table 3). Depression was a risk factor for females only, while being forced to have sex was a risk factor for males. For each risk factor, individuals who experienced these risks were more likely to have smoked cigarettes in the previous 30 days.

In all but one case, a dose-response relationship existed between the risk factor and smoking. For example, of those who had consumed an alcoholic drink on 3 or more days in the previous $30,95.8 \%$ of the females and $86.0 \%$ of the males had also smoked, compared to $63.3 \%$ and $67.7 \%$ of those who had consumed alcohol on 1-2 days, and $14.2 \%$ and $20.4 \%$ of those who reported no alcohol consumption. Furthermore, cigarette use among females who had been in 3 or more physical fights in the past year was $80 \%$; among those who been in 1-2 fights, $42.4 \%$; and among those reporting no physical fights, $23.8 \%$. In addition, of the males who carried a weapon on 2 days, slightly more than $70 \%$ had smoked; 1 day, 57.1\%; and 0 days, $31.6 \%$.

Cigarette smoking was consistently higher among those who had experimented with drugs or alcohol at least once (Figure 1); for example, $24.3 \%$ of those reporting marijuana use also reported having used tobacco during the preceding 30 days as opposed to only $2.4 \%$ of those who had not used marijuana. Likewise, $86.9 \%$ of respondents reporting alcohol consumption in the previous 30 days had smoked tobacco, as opposed to only $35.4 \%$ of those who had not consumed alcohol. Smoking was also significantly higher among adolescents who had used steroids, ecstasy, methamphetamines, heroin, cocaine, and/or other tobacco products.

Results from logistic regression analyses for females indicated that alcohol consumption was the single greatest risk factor associated with cigarette use (Table 4). Adolescent girls who reported having at least one alcoholic drink on 3 or more days in the previous 30 days were 78.7 times (95\% CI: 9.5, 654.0) more likely to smoke tobacco than girls who reported no alcohol consumption. Likewise, females who had consumed at least one drink on 1-2 days were 9.4 times (95\% CI: $3.5,25.0)$ more likely to smoke tobacco than those who reported no alcohol consumption. The only other significant risk factor for smoking among adolescent girls was having been in a physical fight 3 or more times in the past year $(\mathrm{OR}=3.9$; 95\% CI: 1.1, 13.2).

Among adolescent males, smoking was associated with carrying a weapon, having been in a physical fight, having witnessed adults hurting others, drinking alcohol, having had sexual intercourse, and weight perception (Table 4). As was the case with teenage girls, alcohol consumption was the single greatest risk factor for smoking. Specifically, males who reported consuming at least one alcoholic drink on 3 or more days during the previous 30 were 18.2 times $(95 \%$ CI: $5.9,56.2)$ more likely to have smoked tobacco than those who reported no alcohol consumption. Like- 
TABLE 3. Risk factors for tobacco use by sex, Youth Risk Behavior Survey, La Paz, Bolivia, 2004

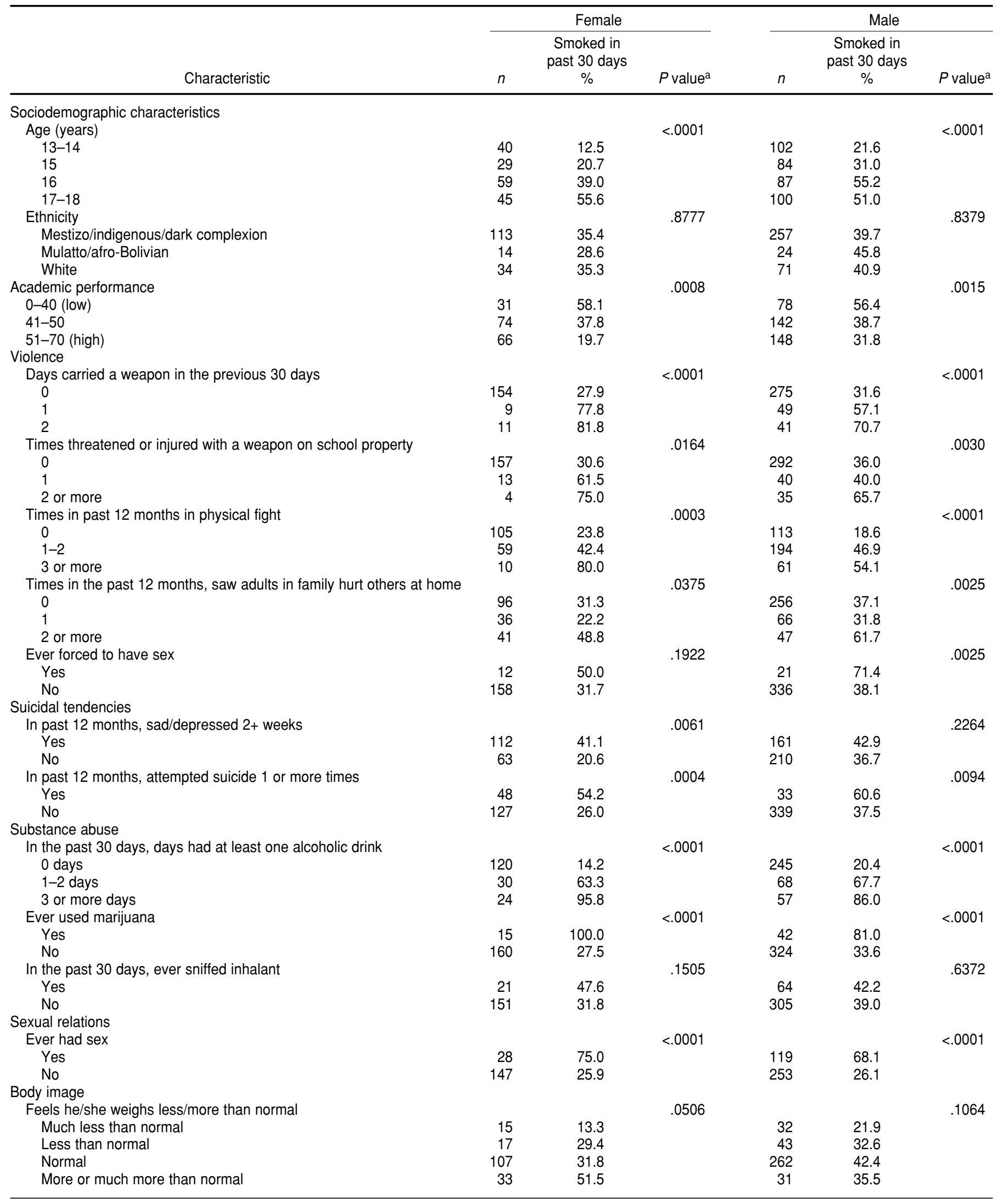

a $P$ values compare categories of respondents of the same sex. 
FIGURE 1. Tobacco as a gateway drug. Drug use in the last 30 days for smokers versus non-smokers, Youth Risk Behavior Survey, La Paz, Bolivia, 2004

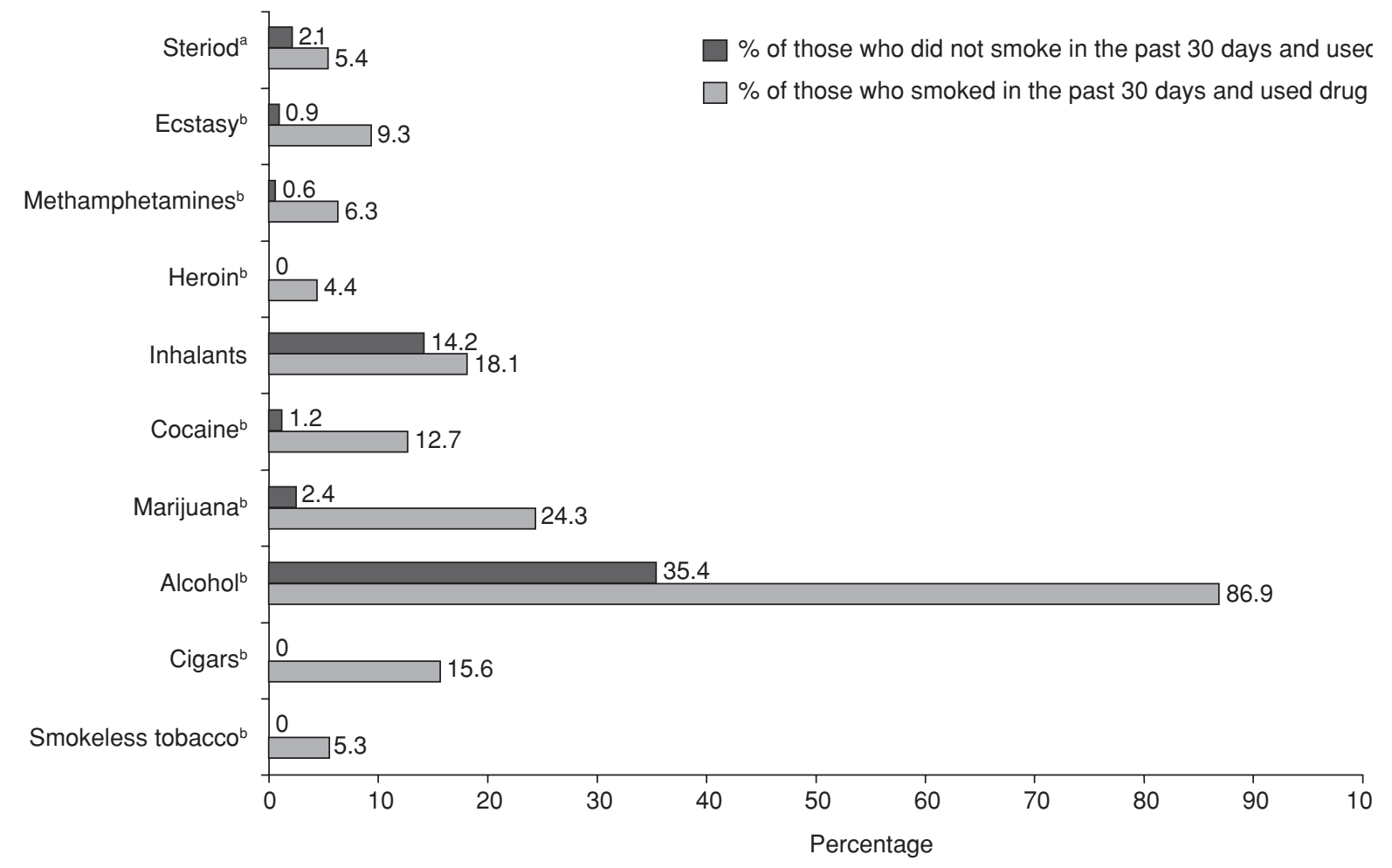

a $P=<.05$.

b $P=<.0001$.

wise, males consuming at least one drink on 1-2 days of the previous 30 were 4.7 times (95\% CI: $2.3,9.7)$ more likely to smoke tobacco than those who reported no alcohol consumption.

When females and males were included in a single model, alcohol consumption remained the single most important risk factor for cigarette use, though age and ethnicity of the respondent-along with violence, sexual relations, and marijuana usewere also correlated with the use of cigarettes (results not shown).

\section{DISCUSSION}

Results from the Youth Risk Behavior Survey conducted in La Paz, Bolivia, indicate that about $40 \%$ of male and female adolescents from 13 to 18 years of age had smoked on 1 or more days in the 30 days preceding the interview. Risk factors for smokingboth for males and females-included age, low academic performance, carrying a weapon, being threatened or injured with a weapon on school property, being in a physical fight, witnessing adults hurting others, attempting suicide, drinking alcohol, using marijuana, and sexual intercourse. Depression was a risk factor for females only, while being forced to have sex was a risk factor for males only. Based on results from logistic regression analyses, alcohol consumption was the single greatest risk factor for cigarette smoking for both males and females. However, violence and aggression (participating in a physical fight and carrying a weapon), and ever having had sexual intercourse were also associated with smoking. Results from this study also confirm the relationship between smoking and the use of other illicit substances and support evidence of tobacco's role as a "gateway drug."

This study is subject to several limitations (19). First, all data come from a single cross-sectional study. As a re- sult, this study is descriptive in nature: smoking trends and causality between smoking and other behaviors cannot be established. Second, the school district was not randomly selected, nor were the respondents within the schools. However, the schools within District II of La Paz were selected randomly. Males are overrepresented in this sample largely because school administrators were more likely to have boys participate. Small sample sizes, particularly among females, contributed to wide confidence intervals and may not have provided enough statistical power to detect an association between smoking and some of the potential risk factors included in the study. Finally, other factors including socioeconomic status, tobacco marketing, peer and family influences, parents' level of education, and attitudes about smoking, which have been linked with teen smoking behaviors in other settings, were not included in this survey instrument (22-25). Conse- 
TABLE 4. Results of logistic regression, factors significantly associated with smoking cigarettes in the past 30 days, Youth Risk Behavior Survey, La Paz, Bolivia, 2004

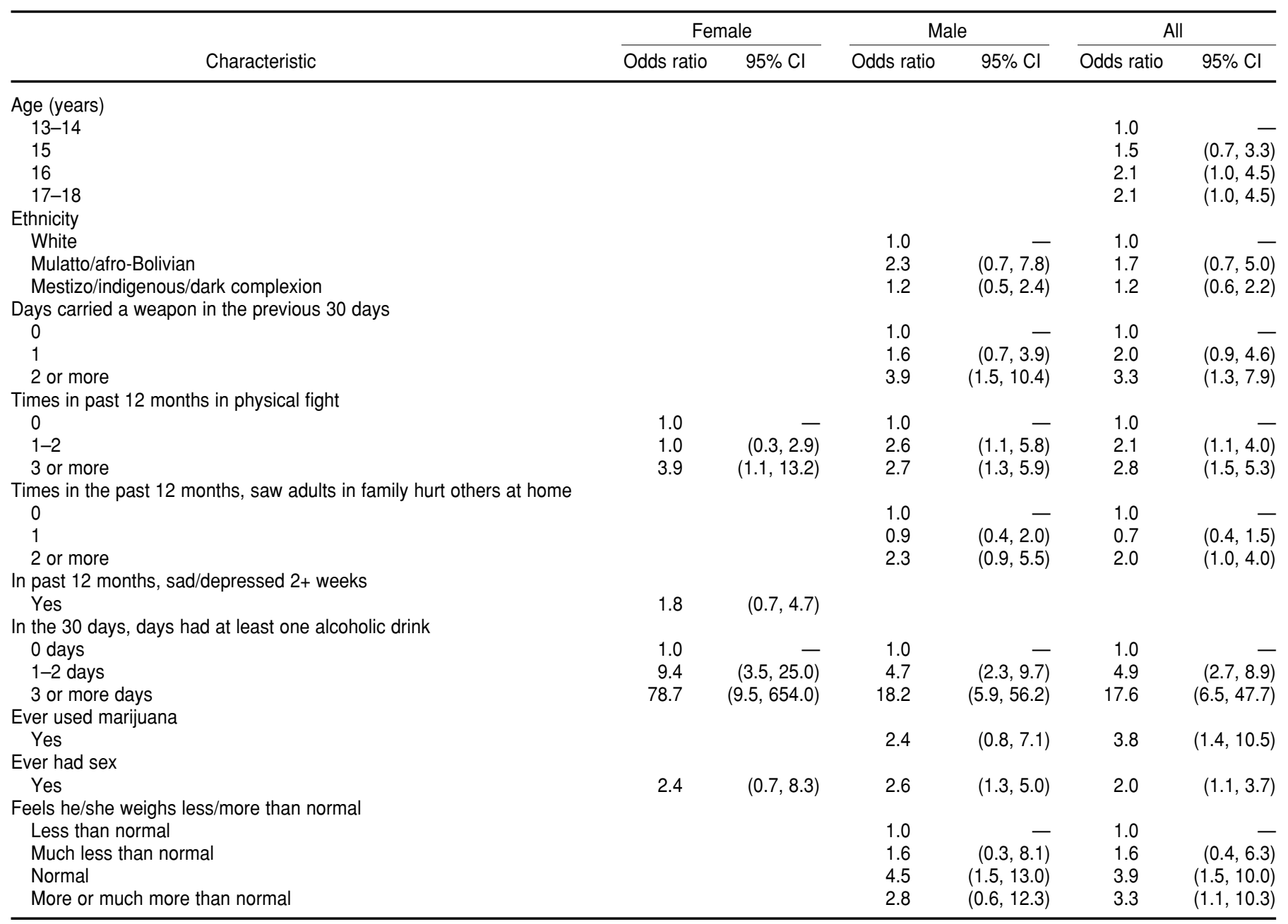

${ }^{\mathrm{a}}$ Cut-off $=0.15$.

quently, this study represents a first step toward shedding light on the relationship between smoking and other risky behaviors among adolescents in La Paz, Bolivia.

Our study results indicate that recent alcohol consumption was the single most important factor associated with cigarette smoking, and that students in La Paz who had smoked in the past 30 days were significantly more likely to have used alcohol, steroids, ecstasy, methamphetamines, heroin, cocaine, and/or marijuana than those who had not smoked. Such findings reflect those of numerous other studies that document an association between cigarette smoking and substance abuse among adolescents $(23,26-30)$. As an example, middle and high school student smokers from Indiana were "three times more likely to drink alcohol, seven times more likely to use smokeless tobacco, and 10-30 times more likely to use illicit drugs than nonsmokers" (15). Similarly, Lee et al. found that among secondary school students in Malaysia who smoked, $11.3 \%$ had used marijuana, $7.3 \%$ had used ecstasy pills, and $4.4 \%$ had tried heroin. From an alternative perspective, $72.6 \%$ of those who had used marijuana, $67.3 \%$ of those who had tried ecstasy pills, and $60.6 \%$ of those who had used heroin were smokers (31).

A variety of sociodemographic factors are thought to contribute to tobacco's role as a gateway drug. More specifically, teenagers that associate with peers who smoke are more likely to also associate with peers who use illicit drugs. Furthermore, most teens perceive rates of drug use among their peers to be much higher than they actually are; thus, drug use is a perceived social norm. Additionally, teens who belong to tobacco-using peer groups are more likely to be given information on how to obtain and use other drugs, and therefore, are more prone to try such drugs (14).

Findings also indicate that adolescents who smoke are at an increased risk for early initiation of sexual activity $(10,32-35)$ and participation in violence-related behaviors (36-40). In our study, Bolivian teenagers who 
were sexually experienced were 2.0 times more likely to have smoked cigarettes in the previous 30 days (95\% CI: 1.1-3.6) than those who had not had sex. Smokers were also more likely to have participated in physical fights and to have carried a weapon than nonsmokers. Similar to our results, Gutierrez et al. found that Mexican teenagers who smoke were 1.5-2.0 times more likely to have sexual intercourse than nonsmokers (33). In addition, a comparison of violence-related behaviors of adolescents in five developed countries (Ireland, Israel, Portugal, Sweden, and the United States of America) found that current smoking was among the best predictors of fighting in all countries (39). DuRant and colleagues also found that carrying a gun, knife, or club on school property was among the best predictors of cigarette smoking among teenagers in North Carolina (38).

Results from this study provide important insights into the relationship between cigarette smoking and other risk behaviors - a relationship that, until now, had not been documented among Bolivian youth. Our results suggest Bolivian teenagers behave in ways similar to teens in the U.S. and elsewhere and that cigarette smoking may serve as an indicator of risk for engaging in other harmful behaviors. Parents, school administrators, and health educators may want to identify teens that smoke and determine whether they engage in violent or aggressive behaviors, are sexually active, or use illicit drugs. Though identifying such students for interventions seems a promising approach to improving the health of adolescents and reducing their participation in risk behaviors, school policies must also be put in place to protect students from discrimination based on their smoking status.

Understanding factors associated with smoking is the first step toward designing and implementing comprehensive programs that simultaneously prevent multiple risk behaviors. Future research among this population should focus on teenagers' motivations for smoking; family, peer, and market influences; identification of factors associated with smoking initiation; and barriers to smoking cessation. Additionally, longitudinal studies are needed to identify how smoking and other behaviors change over time. Efforts to prevent smoking and other risky behaviors in adolescence must begin in early childhood, prior to the initiation of these behaviors, and should include pilot testing of innovative strategies and documentation of the impact of existing programs.

Acknowledgments. We would like to acknowledge the assistance of the Servicio Departamental de Educación (SEDUCA), as well as the administrators, teachers, and students who participated in this research in La Paz. We also extend our appreciation to Daniel Watt and Emily Bennett who collected and entered the majority of the data for this study. Connor McKeown also assisted with collecting data and information for manuscript revisions. Funding was provided by Brigham Young University.

\section{REFERENCES}

1. World Health Organization. Why is tobacco a public health priority? Available from: http:// www.who.int/tobacco/health_priority/en/ index.html . Accessed on 16 March 2006.

2. Pan American Health Organization. The framework convention on tobacco control: strengthening health globally. PAHO; 2001.

3. Elders MJ, Perry CL, Eriksen MP, Giovino GA. The report of the Surgeon General: preventing tobacco use among young people. Am J Public Health. 1994;84(4):543-7.

4. McKinley A. Providers issue brief: Tobacco: Youth access to tobacco. Issue Brief (Health Policy Tracking Service). 31 December 2003: $1-16$.

5. The Global Youth Tobacco Survey Collaborative Group. Tobacco use among youth: a cross country comparison. Tob Control. 2002;11(3): 252-70.

6. Marcus SE, Giovino GA, Pierce JP, Harel Y. Measuring tobacco use among adolescents. Public Health Rep. 1993;108(Suppl 1):20-4.

7. Guindon GE, Boisclair D. Past, current and future trends in tobacco use. Washington, DC: World Bank: 2003. HNP Discussion Paper No. 6. Economics of Tobacco Control Paper No. 6.

8. Pan American Health Organization. The Global Youth Tobacco Survey: results in the Americas. Epidemiol Bull. 2002;23(2):6-9. Available from: http:// www.cdc.gov/tobacco/global/ GYTS/results.htm). Accessed on 20 May 2006.

9. DuRant RH, Smith JA, Kreiter SR, Krowchuk DP. The relationship between early age of onset of initial substance use and engaging in multiple health risk behaviors among young adolescents. Arch Pediatr Adolesc Med. 1999; 153(3):286-91.

10. Ellickson PL, Tucker JS, Klein DJ. High-risk behaviors associated with early smoking: results from a 5-year follow-up. J Adolesc Health. 2001;28(6):465-73.

11. Farrell AD, Danish SI, Howard CW. Relationship between drug use and other problem behaviors in urban adolescents. J Consult Clin Psychol. 1992;60(5):705-12.

12. Ohene S, Ireland M, Blum RW. The clustering of risk behaviors among Caribbean youth. Matern Child Health J. 2005;9(1):91-100.

13. Johnson PB, Boles SM, Kleber HD. The relationship between adolescent smoking and drinking and likelihood estimates of illicit drug use. J Addict Dis. 2000;19(2):75-81.

14. Lindsay GB, Rainey J. Psychosocial and pharmacologic explanations of nicotine's gateway drug function. J Sch Health. 1997;67(4):123-6.

15. Torabi MR, Bailey WJ, Majd-Jabbari M. Cigarette smoking as a predictor of alcohol and other drug use by children and adolescents: evidence of the "gateway drug effect". J Sch Health. 1993;63(7):302-6.

16. Graves KL, Leigh BC. The relationship of substance use to sexual activity among young adults in the United States. Fam Plann Perspect. 1995;27(1):18-22, 33.

17. American Lung Association of San Diego and Imperial Counties. Tobacco as a gateway drug. Available from: http://www.lungsandiego. org/youth/wow_gateway.asp. Accessed on 30 May 2006.

18. Reed JM. International Brief. Population Trends: Bolivia. Available from: http:// www.census.gov/ipc/prod/ib-9801.pdf. Accessed on 20 May 2006.

19. Dearden KA, De La Cruz NG, Crookston BT, Novilla MLB, Clark M. Adolescents at risk: depression, low academic performance, violence, and alcohol increase Bolivian teenagers' risk of attempted suicide. Int Electron J Health Educ. 2005;8:104-19.

20. Brener ND, Kann L, Kinchen SA, et al. Methodology of the Youth Risk Behavior Surveillance System. MMWR. 2004;53(RR12): 1-13.

21. Kolby LJ, Kann L, Collins JL. Overview of the Youth Risk Behavior Surveillance System. Public Health Rep. 1993;108(Supp 1):2-10.

22. Horn KA, Gao X, Dino GA, Kamal-Bahl S. Determinants of youth tobacco use in West Vir- 
ginia: a comparison of smoking and smokeless tobacco use. Am J Drug Alcohol Abuse. 2000;26(1):125-38.

23. Ozcan YZ, Ozcan KM. Determinants of youth smoking-evidence from Turkey. Subst Use Misuse. 2002;37(3):313-36.

24. Padgett DI, Selwyn BJ, Kelder SH. Ecuadorian adolescents and cigarette smoking: a crosssectional survey. Rev Panam Salud Publica. 1998;4(2):87-92.

25. Malcon MC, Menezes AMB, Maia MFS, Chatkin M, Victora CG. Prevalencia e fatores de risco para tabagismo em adolescentes na América do Sul: uma revisão sistemática da literatura. Rev Panam Salud Publica. 2003; 13(4):222-8.

26. Azevedo A, Machado AP. Tobacco smoking among Portuguese high-school students. Bull World Health Organ. 1999;77(6):509.

27. Griffin KW, Botvin GJ, Doyle MM, Diaz T, Epstein JA. A six-year follow-up study of determinants of heavy cigarette smoking among high school seniors. J Behav Med. 1999;22(3): 271-84.

28. Horta BL, Calheiros P, Pinheiro RT, Tomasi E, Costa do Amaral K. [Smoking among teenagers in an urban area in Southern Brazil]. Rev Saude Publica. 2001;35(2):159-64.

29. Martinez JA, Amaya W, Campillo HA, Campo A, Diaz LA. Factores asociados con el con- sume diario de cigarillo en adolescentes estudiantes de basica secundaria de Bucaramanga, Colombia. Biomedica. 2005;25(4): 518-26.

30. Patterson F, Lerman C, Kaufmann VG, Neuner GA, Audrain-McGovern J. Cigarette smoking practices among American college students: review and future directions. J Am Coll Health. 2004;52(5):203-10.

31. Lee LK, Paul CYC, Kam CW, Jagmohni K. Smoking among secondary school students in Negeri Sembilan, Malaysia. Asia Pac J Public Health. 2005;17(2):130-6.

32. Garriguet D. Early sexual intercourse. Health Rep. 2005;16(3):9-18.

33. Gutierrez J, Bertozzi SM, Conde-Glez CJ, Sanchez-Aleman M. Risk behaviors of 15-21 year olds in Mexico lead to a higher prevalence of sexually transmitted infections: results of a survey in disadvantaged urban areas. BMC Public Health. 2006;6(49).

34. Silver EJ, Bauman LJ. The association of sexual experience with attitudes, beliefs, and risk behaviors of inner-city adolescents. J Res Adolesc. 2006;16(1):29-45.

35. Zabin LS. The association between smoking and sexual behavior among teens in US contraceptive clinics. Am J Public Health. 1984; 74(3):261-3.

36. Audrain-McGovern J, Rodriguez D, Tercyak KP, Neuner GA, Moss HB. The impact of self- control indices on peer smoking and adolescent smoking progression. J Pediatr Psychol. 2006;31(2):139-51.

37. DuRant RH, Kahn J, Beckford PH, Woods ER The association of weapon carrying and fighting on school property and the other health risk and problem behaviors among high school students. Arch Pediatr Adolesc Med. 1997;151(4):360-6.

38. DuRant RH, Krowchuk DP, Kreiter SR, Sinal $\mathrm{SH}$, Woods CR. Weapon carrying on school property among middle school students. Arch Pediatr Adolesc Med. 1999;153:21-6.

39. Pesa JA. The association between smoking and unhealthy behaviors among a national sample of Mexican-American adolescents. J Sch Health. 1998;68(9):376-80.

40. Smith-Khuri E, Iachan R, Scheidt PC, Overpeck MD, Gabhainn SN, Pickett W, et al. A cross-national study of violence-related behaviors in adolescents. Arch Pediatr Adolesc Med. 2004;158:539-44.

Manuscript received 7 July 2006. Revised version accepted for publication 10 August 2007.

RESUMEN Objetivo. Describir la prevalencia del consumo de cigarrillos e identificar las conductas de riesgo asociadas con el hábito de fumar en adolescentes de enseñanza media superior de un distrito de La Paz, Bolivia.

Adolescentes en problemas: consumo de cigarrillos y conductas de riesgo en estudiantes de escuelas privadas de enseñanza media superior de La Paz, Bolivia

Métodos. Se aplicó la Encuesta sobre Conductas de Riesgo en los Jóvenes a una muestra de 394 varones y 182 mujeres de 13-18 años de edad de seis escuelas del Distrito II de La Paz seleccionadas al azar. Se identificaron los factores asociados con el consumo de cigarrillos durante los 30 días previos a la encuesta, mediante el análisis de frecuencias, la prueba de la ji al cuadrado y la regresión logística.

Resultados. Aproximadamente $40 \%$ de la muestra (39,4\% de los varones y $33,7 \%$ de las mujeres) había fumado cigarrillos en los 30 días previos a la encuesta. Tanto para ellos como para ellas, el consumo de alcohol fue el mayor factor de riesgo asociado con el consumo de cigarrillos. Los varones y las mujeres que informaron haber consumido al menos una bebida alcohólica en tres ocasiones o más durante los 30 días previos presentaron 22,3 y 58,5 veces (IC95\%: 6,7 a 74,1 y 6,8 a 502,6, respectivamente) mayor probabilidad de fumar que los que informaron no haber consumido alcohol. Otros factores de riesgo adicionales fueron haber participado en una pelea física, haber portado un arma, haber tenido relaciones sexuales y haber tomado alguna droga ilícita durante los 30 días anteriores.

Conclusiones. Debido a que los adolescentes que fuman tienden también a incurrir en otras conductas de riesgo, los padres, los responsables escolares y los educadores sanitarios podrían utilizar el hábito de fumar para identificar a los adolescentes en riesgo. Las intervenciones dirigidas a adolescentes bolivianos deben enfocarse en la prevención del consumo de cigarrillos y de las conductas de riesgo asociadas.

Palabras clave Adolescente, conducta del adolescente, tabaquismo, asunción de riesgos, Bolivia. 